Ann. Génét. Sél. Anim., I977, 9 (I), 517-526.

\title{
Identification of the chromosomes of the domestic pig (Sus scrofa domestica) (1) An identification key and a landmark system
}

\author{
K. M. HANSEN
}

Anatomy Department B, Universitetsparken $I$, DK-2Ioo Copenhagen $ø$, Denmark

\section{Summary}

According to the Q-, G-, and R-(BudR) band patterns, a key for identification of the chromosomes of the domestic pig (Sus scrofa domestica) is presented. In the diagrammatic presentation of the banding patterns, all the regions and bands of the nineteen pairs of chromosomes are numbered. Furthermore, a landmark system based on the $Q$ - and G- band pattern is presented.

Several different arrangements of pig chromosomes in karyotype have been used in recent years, even since introduction of banding methods. The reason for this confusion seems to be that no arrangement of chromosomes has been full accepted until now. There are several reasons for this. One reason is that identified chromosomes have not been measured and then placed in a karyotype according to decreasing length or to another logical system.

The pig chromosomes in this paper are placed into the karyotype system recommended at the Reading Karyotype Conference 1976.

\section{Materials and Methods}

Chromosomes from forty pigs, I4 boars and 26 sows from different strains of pure Danish Landrace, were examined. Only cultures from blood were examined. The blood was taken from the jugular vein and stabilized by Heparin (Leo). Cultures were prepared as a suspension of blood in autologues plasma and tissue culture medium I99 (Flow); $0.1 \mathrm{ml}$ phytohaemagglutinin (Wellcome) was added per $5 \mathrm{ml}$ culture suspension. The cultures were incubated 48 hours at $38^{\circ} \mathrm{C}$. Three hours before harvesting one drop $0.02 \mathrm{p}$. cent $\mathrm{v} / \mathrm{w}$ colcemid solution

(i) This article has been presented at the $3^{\text {rd }}$ Colloquium of Cytogenetics of Domestic Animals, May 3I-June 2, I977, Jouy-en-Josas, France. 
(Ciba) was added per $5 \mathrm{ml}$ culture suspension; hypotonic treatment with $0.3 \mathrm{p}$. cent $\mathrm{KCl}$ solution for 5 minutes; fixing in acetic acid/methanol $\mathrm{I}: 3$.

The $Q$-band staining was carried out according to the method described by CASPERSSON et al. (I969), slightly modified for animal chromosomes by HANSEN (1972). The G-band staining was carried out according to the trypsin method described by WANG and FEDOROFF (I972), slightly modified. The R-band staining method used was described by DUTRILLAUX et al. (I973), but the incubation time with BudR (Sigma) and colcemid solution was modified to 7 hours.

As basis for an exact identification of the banding patterns in figure $I$, and for the diagram demonstrated in figure 2, the three staining methods mentioned above were used on metaphase plates as double staining methods. According to HANSEN $(I 975 / b)$ the order of these methods were $Q$-band/R-band staining, G-band $/ Q$-band staining and $Q$-band/Conventional Giemsa staining. The Q-band/Conventional Giemsa staining method, which presumably until now is the only method which combines identification of chromosomes with possibilities for exact measurements of the chromosome length and the centromere position, is used for the results shown in Table $I$.

\section{TABLE I}

Relative length and arm ratio of the mitotic chromosomes of the domestic pig, (Sus scrofa domestica). Mean of ro cells

Longueur relative et rapport des bras de chromosomes mitotiques du porc domestique (Sus scrofa domestica).

Moyenne sur to cellules

\begin{tabular}{|c|c|c|c|c|c|c|c|c|c|c|c|c|c|}
\hline & Pair & & No. & & $\begin{array}{c}\text { Relative } \\
\text { length }\end{array}$ & $\frac{q}{p}$ & Term (*) & Pair & No. & & $\begin{array}{l}\text { Relative } \\
\text { length }\end{array}$ & $\frac{q}{p}$ & Term $\left(^{*}\right)$ \\
\hline I & . . & . & . & . & II. 9 & 2.I & $s m$ & $\| \mathrm{II}$. & . . & . . & 2.9 & $\mathbf{I . 2}$ & $m$ \\
\hline 2 & . . & . & . & . & 6.I & 2. I & $s m$ & I2 & . . & . . & 2.5 & I. 2 & $m$ \\
\hline 3 & $\cdot \cdot$ & . & . & . & $5 \cdot 7$ & 1.9 & $s m$ & I3 & . . & . . & 9. I & 一 & $t$ \\
\hline 4 & $\cdot \cdot$ & . & . & . & $5 . \mathrm{I}$ & 2.0 & $s m$ & I4 . & . . & . & 6.2 & - & $t$ \\
\hline 5 & . . & . & . & . & 6.9 & 3.4 & $s t$ & I 5. & . . & . & 5.8 & 一 & $t$ \\
\hline 6 & . . & . & . & . & $5 . \mathrm{I}$ & $3 \cdot 5$ & $s t$ & I 6. & . . & . . & $3 \cdot 7$ & - & $t$ \\
\hline 7 & $\cdot \cdot$ & . & . & . & $5 \cdot 5$ & 1. 6 & $m$ & I 7. & . . & . . & 2.7 & - & $t$ \\
\hline 8 & $\cdot \cdot$ & . & . & . & 5.1 & I. 3 & $m$ & I 8. & . . & . . & 2.4 & - & $t$ \\
\hline 9 & . . & . & . & . & 4.2 & I. 5 & $m$ & I9 X. & . . & . . & $5 \cdot 3$ & I. I & $m$ \\
\hline xo & . . & . & . & . & 4.0 & I.o & $m$ & X. & . . & . . & I. 7 & I. 3 & $m$ \\
\hline
\end{tabular}

(*) Accotding to Levan et al. (I964).

The chromosomes are arranged in karyotype according to the system of LEVAN et al. (I964), modified by the Reading Conterence 1976: Row I, submetacentric chromosomes $(\mathrm{sm})$; row 2, subtelocentric chromosomes $(s t)$; row 3, metacentric chromosomes $(m)$; row 4 , acrocentric/telocentric chromosomes $(t)$. The sex chromosomes are kept apart. Inside the groups the chromosomes are placed according to decreasing length.

Banding patterns for pig chromosomes previously described by other authors, Table 3 , have been studied carefully and compared to the present results. 
TABLE 2

Bands serving as landmarks which divide the chromosomes into cytologically defined regions Bandes servant de "landmarks " qui divisent les chromosomes en des régions cytologiques précises

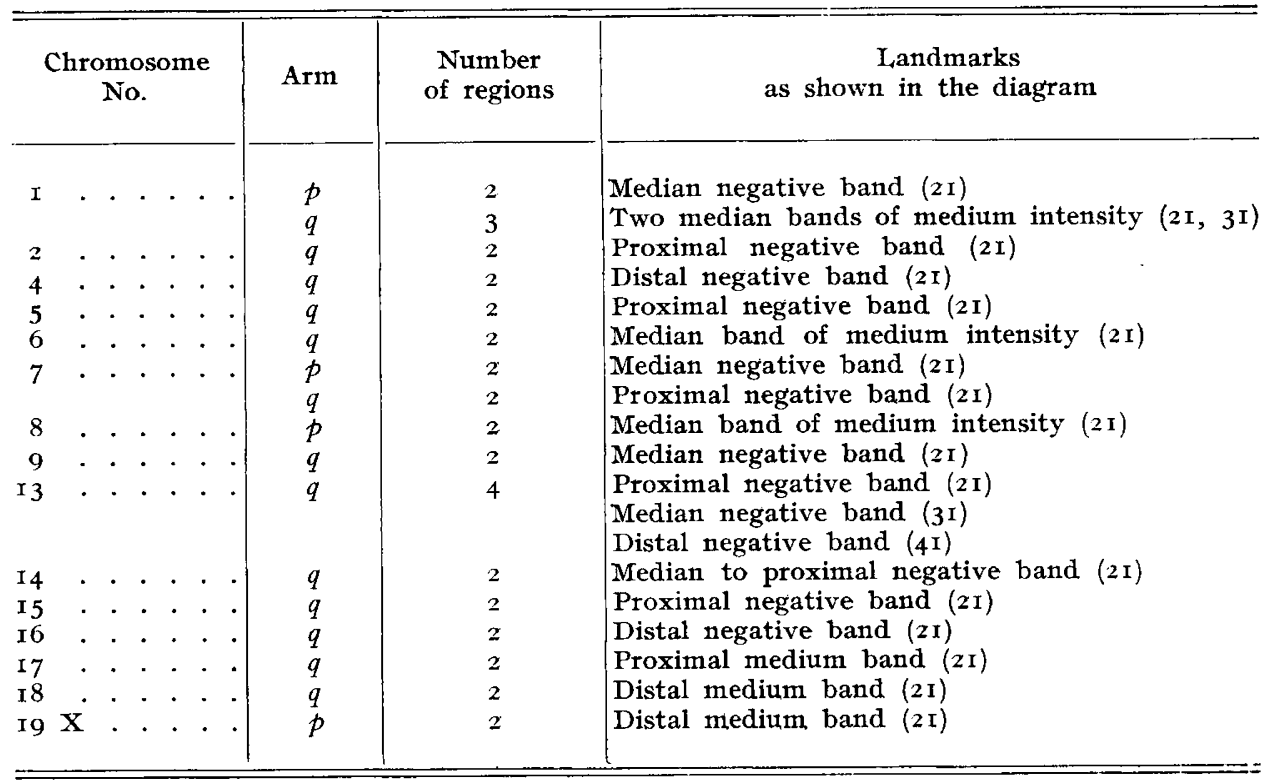

TABLE 3

Authors, who have investigated pig chromosomes by banding methods Auteurs ayant utilisé les techniques de marquage chez le porc

\begin{tabular}{|c|c|c|}
\hline Authors & Year & Band investigated \\
\hline 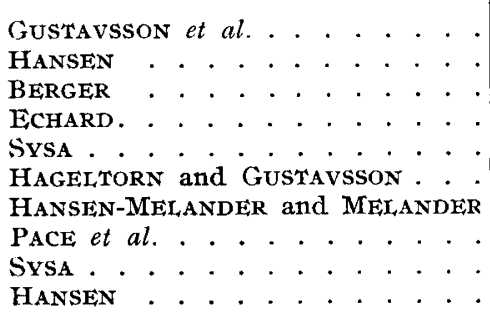 & $\begin{array}{l}1972 \\
1972 \\
1972 \\
1973 \\
1973 \\
1973 \\
1974 \\
1975 \\
1975 \\
1976\end{array}$ & $\begin{array}{l}\text { Q-band } \\
\text { Q-band/Conventional Giemsa } \\
\text { G-band } \\
\text { G-band } \\
\text { Q-band } \\
\text { Q-band/G-band } \\
\text { G-band, C-band } \\
\text { G-band } \\
\text { G-band } \\
\text { G-band /Q-band, Q-band /C-band, R-band }\end{array}$ \\
\hline
\end{tabular}




\section{Results}

A detailed description of the different pairs of chromosomes is as follows. First the bands which serve as landmarks in Q- and G-band stained cells are stated, then there are the most typical G-, Q-, and R-band patterns for each of the nineteen pairs of chromosomes. The different banding patterns are depicted in figure $\mathbf{I}$. The numbers of the bands are indicated on the diagram in figure 2 .

In general the differences between the Q-, G-, and R-band patterns can be described as follows. The G-band staining method visualizes the number of positive bands and their position very clearly. By the $Q$-band method, with the dif-

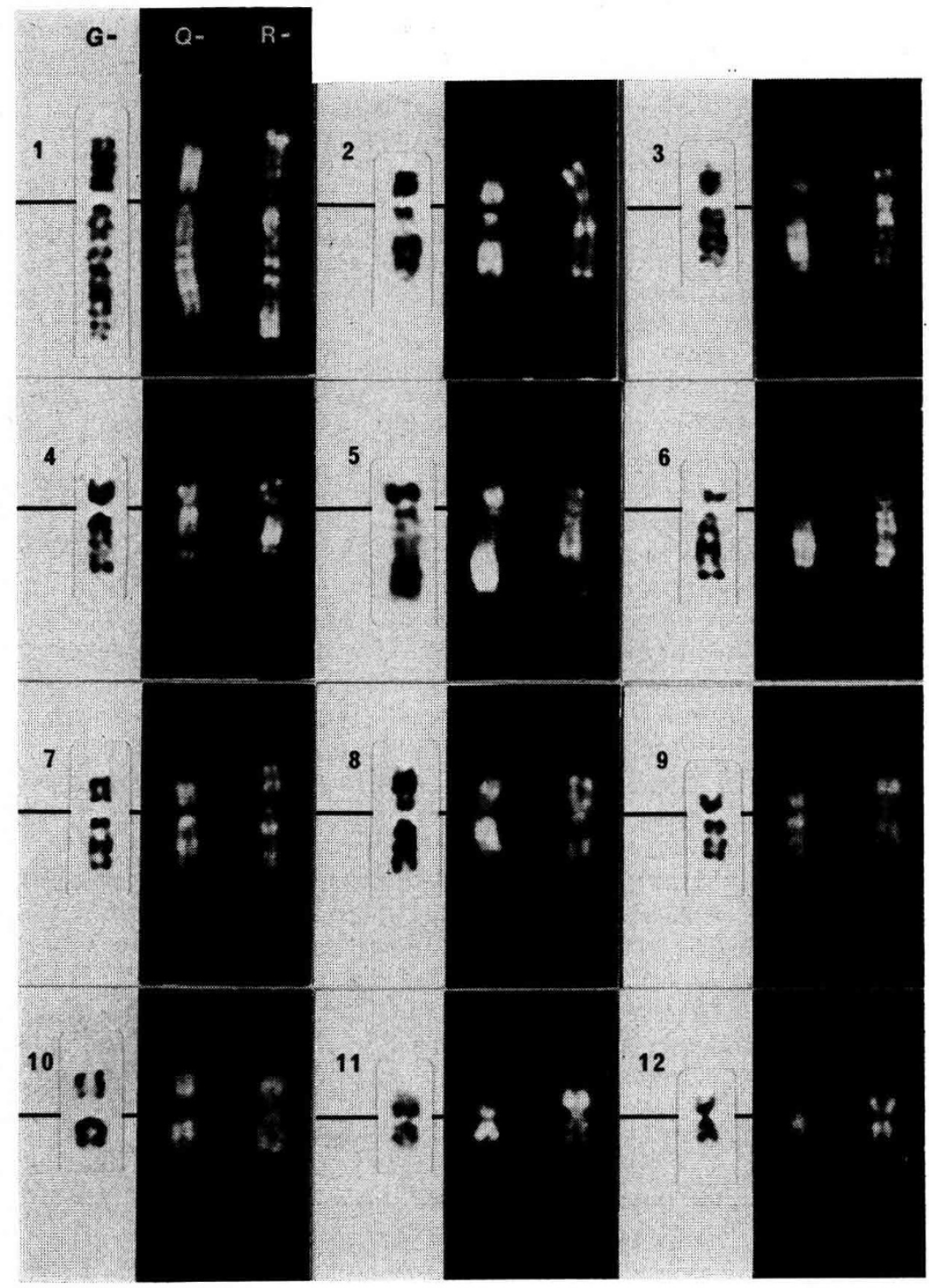




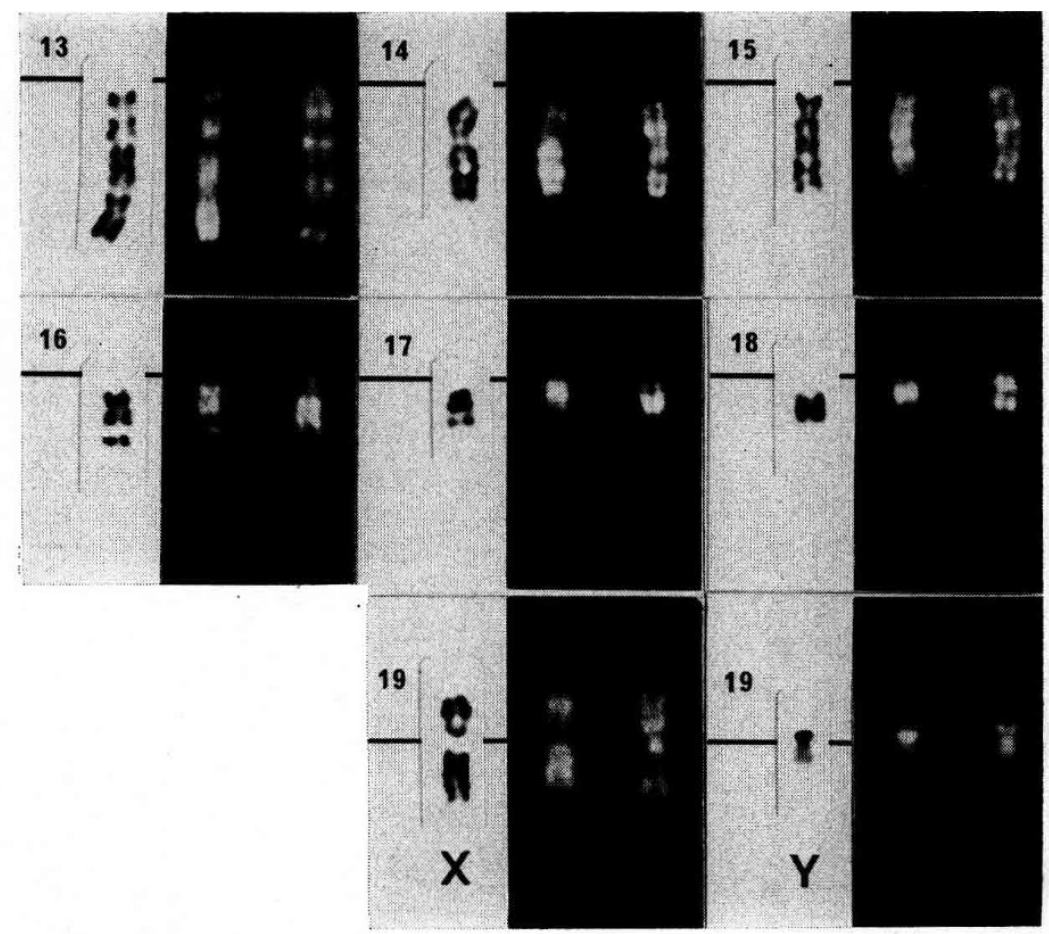

FIG. I. - The G-, Q-, and R-band patterns of the autosomes and the sex chromosomes of the domestic pig.

Bandes $G, Q$ et $R$ des autosomes et des gonosomes $d u$ porc domestique.

ferent intensity of the fluorescence of the different bands, a very easy and exact identification of all the chromosome pairs is possible. However, this method is perhaps the most difficult method to use, because the quality of the cells must be very high. With respect to band identification, the R-band (BudR) staining method seems to be the best method for routine identification cf chromosomes, because the incidence of metaphase plates with chromosomes which show "good bands" seems to be higher by this method as compared to the two other methods.

The differences in the banding pattern by the three staining methods are obvious, figure I, and for that reason they support each other very well.

Landmarks are indicated by $\mathrm{L}$, short arms by $p$, and long arms by $q$. GTG indicates G-bands according to the trypsin method, Paris Conference (I97I), Supplement (I975). QFQ indicates $Q$-bands by fluorescence using quinacrine, and RBA indicates R-bands by BudR using acridine orange. No comments are indicated by - . The terms distal and proximal refer to the position of bands or parts of arms in respect to the centromere.

Pair No. I. L : usually a negative band on the middle of $p$, and two small intense bands on the middle of $q$. $(p)$ : four bands by GTG, often equal fluorescence by $\mathrm{QFQ}$; distinct band at the distal end by RBA. $(q)$ : six bands by GTG; nos. I.3, 3.3 and 3.5 are often subdivided. The distal bands are very often pale by $Q F Q$. Pair No. 2. L: a very broad negative band on the proximal part of $q .(p)$ and $(q)$ : 

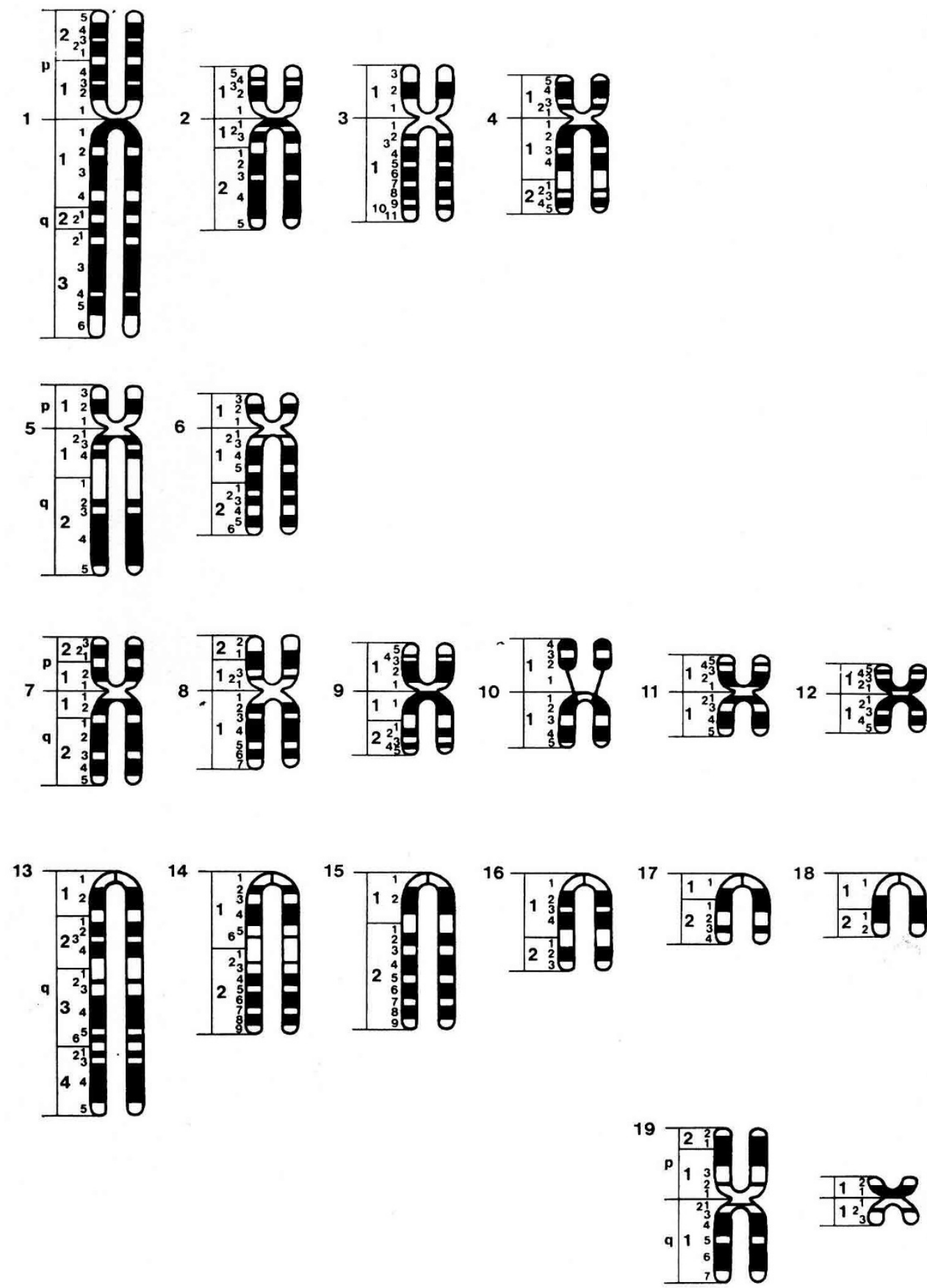

FIG. 2. - Diagrammatic representation of chromosome bands as observed by the $Q_{-}^{-}, G_{-}$, and $R$-band staining methods

Représentation schématique des bandes sur les chromosome observés $\grave{a}$ l'aide des techniques de marquage $Q, G$, et $R$ 
-. Pair No. 3. No landmarks. $(p)$ : a distinct band by GTG, which is very pale by QFQ. $(q)$ : five equally spaced bands by GTG. Pair No. 4. L: a very broad negative band on the distal end of $q .(p)$ and $(q)$ : - . Pair No. 5. L: a very broad negative band on the proximal part of $q .(p):-.(q)$ : havy staining by GTG, and intense fluorescence by $Q F Q$ of the distal part. Pair No. 6. L: a distinct band on the middle of $q .(p)$ : a distinct band by GTG, which is very pale in QFQ. $(q)$ : -. Pair No. 7. L: distinct negative bands on the middle of $p$ and on the proximal part of $q .(p)$ : two bands of the same width by GTG and QFQ. $(q)$ : three bands by GTG and QFQ, equally spaced. Pair No. 8. L: a broad band on the middle of $p$. This chromosome is very similar to the $\mathrm{X}$, but the $\mathrm{X}$ chromosome has a very broad band at the end of $p .(p)$ and $(q)$ : - . Pair No. 9. L: a distinct negative band on the middle of $q .(p)$ : as the bands are placed on the proximal part of $p$, this chromosome looks like a submetacentric chromosome in Q- and G-band staining. The distal one third is very distinct by RBA. $(q)$ : -.. Pair No. Io. No landmarks. $p$ has a very distinct secundary constriction in the proximal part. $(p)$ and $(q):-$. Pair No. II. No landmarks. $(p)$ : the distal band is very pale by GTG and QFQ and looks like an aerial wire. This distal part is very distinct by RBA. $(q)$ : - . Pair No. I2. No landmarks. $(p)$ and $(q)$ : - . Pair No. I3. L: q divided into four nearly equal parts by three broad negative bands. $(q)$ : four band areas are visible by QFQ. By GTG, these four band areas are subdivided into eight bands. Pair No. I4. L: a broad negative band on the proximal part of $q .(q):-$. Pair No. I5. $\mathrm{L}$ : a distinct negative band near the centromere region. $(q)$ : five bands of nearly the same width by GTG and QFQ. Pair No. I6. L: a broad negative band on the distal part of $q .(q)$ : - - Pair No. I7. L: a broad band near the centromere region. $(q)$ : - . Pair No. I8. L: one band on the middle of $q .(q)$ : -. Pair No. I9. The $X$ chromosome. L: a broad band near the end of $p .(p)$ : by GTG and QFQ, this band seems to be at the end of $p$. By RBA, only a small dot is visible near the telomere. $(q)$ : - - The $\mathrm{X}$ chromosome is very similar to pair No. 8. The $Y$ chromosome. The smallest chromosome of the complement. ( $p)$ : by GTG and QFQ, a very distinct band on the proximal part. $(q)$ : - . Medium fluorescence. The bands which serve as landmarks are described in Table 2.

\section{Discussion and Conclusion}

In principle it is possible to arrange the chromosomes in a karyotype in many ways. If it is possible to arrange the chromosomes according to a logical system or to a system in which the chromosomes are easy to identify, this system would have to be a good change in order to be accepted.

The pig karyotype has until now been published in different ways. Makino et al. (I962) roughly divided the pig chromosomes into bi-armed /one-armed groups, except for the small metacentric ones, and arranged the chromosomes apparently by decreasing length. Clausen and Syverton (I96z) divided the chromosomes into bi-armed /one-armed groups, but not according to decreasing length. McConNer et al. (I963) mixed the bi-armed/one-armed chromosomes according to the system of the human chromosome study group r96o (Denver group), i.g. roughly according to decreasing length. STONE (I963) divided the pig chromosomes into two groups, bi-armed and one-armed, and arranged the chromosomes according to decreasing length. MCFEE et al. (I966) put all the acrocentric chro mosomes in one row, but this row was placed between the rows of submetacentric/ 
metacentric chromosomes. The systems of MCConner et al. (r963), Stone (r963), and MCFEE et al. (I966) were used by many authors.

By introduction of the banding pattern of the pig chromosomes, Gustavsson et al. (I972) roughly used the principles for a karyotype system by LEVAN et al. (I964), but without measurements of the chromosomes and with another order of the bi-armed chromosomes. At the same time Hansen (I972) used the karyotype system of MCFEE et al. (I966), without measurements of the chromosomes either.

At the Reading Karyotype Conference 1976 it was decided to recommend the use of the system of LEVAN et al. (I964). However, the recommended order for the bi-armed chromosomes do not agree with the Levan system $(m, s m, s t, t)$, but were modified to $s m, s t, m$, and $t$. One chromosome pair was placed in a wrong group, because no measurements of pig chromosomes were taken into consideration at the Conference.

The karyotype presented in this paper uses the recommended order of the bi-armed chromosomes from the Reading Conference, and inside the groups $s m$, $s t, m$, and $t$, the chromosomes are placed according to decreasing length, Table I. Furthermore, the chromosome pair which was placed in a wrong position according to the arm ratio, pair No. 9 in Fig. $I$, is now placed in the $m$ group.

By the new banding methods, it seems unnecessary to subdivide the bi-armed chromosomes, because the identification is very easy. The bi-armed/one-armed karyotype system has until now been used for the G-band pattern of pig chromosomes by BERGER (I972) and ECHARD (I973). This system is used by MANDAHL and FREDGA (I975) for the banding pattern of mink chromosomes, and seems to the author to be a good working system for comparative studies, HANSEN (I975a, I976), even if the Levan system is excellent for comparative studies, too, ARNASON (I974).

Results from other authors, who have worked out identification systems for pig chromosomes, Table 3, are taken into consideration by the display of the diagram, figure 2 .

If the chromosomes are very long, it is possible to get more bands than shown in the diagram on figure 2 . These bands should then be numbered according to the nomenclature of the Paris Conference, I97I. In metaphase plates with very long chromosomes, e.g. the band I735 is subdivided into two equal bands. These bands should thus be numbered Iq35.I, Iq35.2 (a negative band), and Iq35.3, the Iq35.I being proximal to the centromere.

If an exact identification of bands on chromosomes are desirable, the chromosomes must be stained by at least two banding methods (HANSEN I975b), because different banding methods, e.g. Q- and R-bands, support each other very well. In some cases it is difficult to separate two pairs of chromosomes by one staining method, but easy by anoter.

Pairs No. 2 and No. 7 are easy to separate in Q- and G-band stained cells, because $q$ in No. 2 has a proximal broad negative band, while $q$ in No. 7 is divided into three nearly equal parts. By R-band staining, however, Nc. 2 and No. 7 are difficult to separate, but in No. $7, p$ has two R-bands distally. In some cells pairs No. 3 and No. 6 are difficult to separate in Q-band stained cells, but $q$ has $a$ row of equally distinct bands in No. 3, while $q$ has an intense band on the middle in No. 6. In R-band stained cells No. 3 and No. 6 are easy to separate, because of the different length of the short arms. Pairs No. 3 and No. 8 are sometimes difficult to separate in R-band stained cells, but No. 3 has a more intense fluorescence on $p$ and $q$ proximal to the centromere. Furthermore, No. 8 has a club- 
shaped band at the end of $q$. In R-band stained cells pair No. 3 and the $X$ chromosome are difficult to separate, too. Again No. 3 has a more intense fluorescence on $p$ and $q$ proximal to the centromere compared to the $\mathrm{X}$ chromosome. It is characteristic that the $\mathrm{X}$ chromosome has a very broad negative band on the middle of $q$. Pair No. 8 and the $X$ chromosome are very difficult to separate by G-band staining. No. 8 has a distinct band on the middle of $p$. The $\mathrm{X}$ chromosome has a broad band near the distal end of $p$. By $Q$-band staining it is easy to separate these two chromosomes in good cells. By $\mathrm{R}$-band staining only a small dot is visible on the distal end of the $\mathrm{X}$ chromosome, while No. 8 has two equal broad bands on $p$. In $Q$ - and G-band stained cells pair No. 9 seems to be a submetacentric chromosome, while it is a very clear metacentric chromosome in an R-band stained cell. The secondary constriction in pair No. Io is not visible in G- and $Q$-band stained cells, but shows a very pale fluorescence by $\mathrm{R}$-band staining. If the chromosomes are not very long it is difficult to separate No. II and No. I2 in $Q$-band stained cells, but in R-band stained cells $p$ shows a very intense fluorescence on the distal part of No. II. Of the acrocentric group, pairs No. I4 and No. $I 5$ are usually very easy to separate by $Q$ - and G-bands, but in some cells they are difficult to separate by R-bands.

For these reasons all the basic band methods should be used for identification of the pig chromosomes.

$$
\text { Reçu pour publication en décembre } 1977 .
$$

\section{Résumé}

Identification des chromosomes du porc domestique (Sus scrofa domestica), Clés pour l'identification et système de repérage

Identification des chromosomes du porc domestique (Sus scrofa domestica) à l'aide des bandes Q-, G-, R (BUDR) est présentée. Toutes les régions et bandes des I9 paires de chromosomes sont numérotées sur un diagramme. Un système de repères basé sur les bandes $Q$ et $G$ est aussi proposé.

\section{Acknowledgements}

The author wishes to thank laboratory technicians Mrs. Else HANSEN and Bente KJAERSGAARD for skillful assistance. The work was supported by the Danish Agricultural and Veterinary Research Council, Grant No. 5I3-I55I/72 and No. 513-2534/73.

\section{References}

Arnason U., I974. Comparative chromosome studies in Cetacea. Hereditas, 77, I-36.

BERGER R., I972. Étude du caryotype du porc avec une nouvelle technique. Exptl. Cell Res., 75, 298-300.

Caspersson T., Zech L., Modest E. I., Foley G. E., Wagh U., Simonsson E., I969. Chemical differentiation with fluorescent alkylating agents in Vicia faba metaphase chromosomes. Exptl. Cell Res., 58, 128-140.

Clausen J. J., Syverton J. T., I962. Comparative Chromosomal Study of 3 I Cultured Mammalian Cell Lines. J. Natl. Cancer Inst., 28, I I 7-145. 
Dutrilifaux B., laAurent C., Couturier J., Lejfune J., r973. Coloration des chromosomes humains par l'acridine orange apres traitement par le 5 bromodéoxyuridine. C.R. Acad. Sc. Paris, 276, Série D, 3179-3181.

ECHARD G., I973. Étude des bandes chromosomiques du porc et de trois différentes souches de rein du porc en culture (PK I5, F et RP). Ann. Génét. Sél. Anim., 5, I-2 r.

Gustavsson I., HAGeltorn M., Johansson C., ZECH L., I972. Identification of the pig chromosomes by the quinacrine mustard fluorescence technique. Exptl. Cell. Res., 70, 471-474.

Hageltorn M., Gustavsson I., I973. Giemsa staining patterns for identification of the pig mitotic chromosomes. Hereditas, 75, I44-146.

HANSEN K. M., 1972. The karyotype of the pig (Sus scrofa domestica), identified by quinacrine mustard staining and fluorescence microscopy. Cytogenetics, 11, 286-294.

HANSEN K. M., I975 a. The G- and Q-band karyotype of Böhm's or Grant's zebra (Equus burchelli böhmi). Heveditas, 81, I33-I 40 .

Hansen K. M., I975 b. Animal chromosomes and banding methods. Proceeding of: 2. Europäisches Kolloqnium über Zytogenetik (Chromosomenpathologie) in Veterinärmedizin, Tierzucht und Säugetierkunde. Giessen 29. und 3o. September 1975. 33-43.

HANSEN K. M., 1976. The karyotype of the pig. Contribution to the Reading Karyotype Conference, 2nd-6th August 1976. Unpublished results.

HANSEN-Melander E., MELander Y., I974. The karyotype of the pig. Heveditas, 77, $149-\mathbf{1} 5$.

LEVAN A., Fredga K., SANDBERG A. A., I 964 . Nomenclature for centromeric position on chromosomes. Hereditas, 52, $201-220$.

Makino S., SaSaki M. S., Sofuni T., Ishikawa T., I96z. Chromosome Condition of an Intersex Swine. Proc. Jap. Acad., 38, 686-689.

MANDAhL N., FredGa K., 1975. Q-, G- and C-band patterns of the mink cluromosomes. Hercditas, 81, 2 I I -220 .

MCCONNELI. J., Fechreimer N. S., Gilmore L. O., I963. Somatic chromosomes of the domestic pig. J. Animal Sci., 22, 374-379.

MCFEE A. F., KNIGHT N., BANNER M. W., I966. An intersex pig with XX/XY leucocyte mosaicisms. Can. J. Genet. Cytol., 8, 502-505.

Pace J. W., Srivastava P. K., Lasiey J. F., i975. G-band patterns of swine chromosomes. J. Heved., 66, 344-348.

Paris Conference (I97I): Standardization in Human Cytogenetics. Birth Defects: Original Article Series, VIII, 7, r972. The National Foundation, New York.

Paris Conference (I97I), Supplement (I975): Standardization in Human Cytogenetics. Birth Defects: Original Article Series, XI, 9, 1975. The National Foundation, New York.

STONE L. E., I 963 . A chromosome analysis of the domestic pig (Sus scrofa) utilizing a peripheralblood culture technique. Can $J$. Genet. Cytol., 5, 38-42.

SysA P., I973. Fluorescence characteristics of the karyotype of the pig. In Iitro, 2/2A, 56-67.

Sysa P., I975. Studies on the karyotype of domestic pig (Sus scrofa dom.) by means of banding patterns techniques and autoradiagraphy. Proceeding of: 2. Europäisches Kolloquium über Zytogenetik (Chromosomenpathologie) in Veterinärmedizin, Tierzucht und Säugetierkunde. Giessen 29. und 30. September 1975. 83-9r.

WANG H. C., FEDOROFF S., I972. Banding in human chromosomes treated with trypsin. Nature New Biol., 235, 52-53. 